\title{
UM ESPECTRO \\ RONDA A \\ SELVA: HISTÓRIA, ANTROPOLOGIA E PRÁXIS
}

\section{Gustavo Velloso}

Universidade de São Paulo

São Paulo - São Paulo - Brasil

Resenha do livro: TIBLE, Jean. Marx selvagem. São Paulo: Annablume, 2013.

O livro Marx selvagem, de Jean Tible, reconduz para a arena das ciências humanas um horizonte analítico que vinha sendo desdenhado há décadas, depois de ter se beneficiado do contexto teórico e político particularmente favorável do início do século XX até os anos 1980, em todo o mundo. Trata-se do aproveitamento do materialismo histórico, enquanto tradição de análises e reflexões, para o estudo de formações sociais diferentes daquela que constituiu o eixo central das preocupações de seus primeiros pensadores, isto é, a sociedade capitalista em seu clássico formato industrial. No caso, as populações indígenas do continente americano são o foco da reflexão.

Mestrando pelo Programa de Pós-Graduação em História Social da Faculdade de Filosofia, Letras e Ciências Humanas e bolsista da Fundação de Amparo à Pesquisa do Estado de São Paulo.E-mail: gustavo.velloso@usp.br; gustavo.velloso@hotmail.com. 
Fruto de uma tese de doutorado defendida em 2012 na Unicamp, a obra recebeu até agora bom acolhimento, ${ }^{1}$ o que pode ser atribuído não apenas ao fato de que o livro atende a uma demanda dos intelectuais e movimentos políticos de esquerda que não se contentam com o corrente tratamento dos problemas indígenas como uma questão "de minorias", mas também à situação especialmente crítica pela qual as populações indígenas do Brasil (e também de fora dele) têm passado nos últimos anos. Refiro-me ao avanço da exploração econômica sobre reservas e extensões florestais em benefício do agronegócio e de megaprojetos garantidos por governos neoliberais e/ou desenvolvimentistas cada vez menos aparelhados para conter os efeitos devastadores de suas próprias práticas políticas.

Tible nos instiga a pensar, então, se o horizonte marxista (e, junto dele, seu método dialético, potencial crítico e de autocrítica permanente) não seria portador de instrumentos válidos de compreensão, investigação e, evidentemente, transformação dessa realidade. Sua resposta é positiva e, nesse sentido, demonstra-se que resgatar Karl Marx (1818-1883) e Friedrich Engels (1820-1895) para pensar as (e com as) populações indígenas americanas não significa projetar sobre elas conclusões e categorias formuladas por esses dois teóricos em outros contextos - para o autor isso se mostra, aliás, prescindível -, mas não ignorar os tipos de questão por eles colocados para as sociedades anteriores e/ou contemporâneas do capital e que, estranhas à sua lógica, sentem ou sentiram as consequências de sua expansão.

O argumento é atraente e bem delineado. Divide-se em três grandes momentos e cada qual corresponde a um capítulo da obra. Em primeiro lugar, diz-nos, os escritos de Marx e Engels apresentam certa sensibilidade com relação a formações sociais externas ao continente europeu, incluindo o que se convencionou chamar de "sociedades primitivas". Segundo, a crítica do Estado contida nos textos dos dois filósofos alemães combinaria com os mecanismos de "recusa" do Estado vistos em grupos ameríndios pelo antropólogo francês Pierre Clastres (1934-1977). Finalmente, a organização autônoma dos Yanomami e os textos de Davi Kopenawa (1956-), uma de suas lideranças, retratariam os bons frutos advindos da aproximação "Marx-América indígena", sobretudo a partir da crítica que Kopenawa fez daquilo

\footnotetext{
1 A publicação do livro rendeu ao autor entrevistas, lançamentos e debates em lugares como México, Rio de Janeiro, Salvador e São Paulo, incluindo lançamento no lendário Teatro Oficina de São Paulo, com a participação de José Celso Martinez Corrêa e do filósofo Toni Negri, entre outros.
} 
que Marx concebeu como fenômeno ludibriante da nossa sociedade, o "fetichismo da mercadoria".

O ponto de partida adotado pelo autor foi o pensamento do revolucionário peruano José Carlos Mariátegui (1894-1930), segundo Tible "precursor" (p. 18) da mobilização do marxismo para as pautas indígenas e indigenistas. Mariátegui teria rompido com uma visão eurocêntrica que enxergava os índios americanos pela ótica do atraso social e teria apontado nos ayllu (unidade comunitária básica de organização andina durante o período incaico) a existência de características avançadas de produção comunitária, apesar de a parcimônia dos contatos de Mariátegui com as comunidades indígenas ter fragilizado, em parte, sua obra.

Passando ao exame dos escritos de Marx e Engels (capítulo 1), o autor destaca a existência de referências a povos não europeus (Índia, China, Argélia, México, Irlanda, Estados Unidos, Rússia etc.) em escritos de várias fases de suas obras, encontradas tanto em A ideologia alemã (1845-6) como em textos posteriores ao primeiro volume de $O$ capital (1867), ou ainda no Manifesto do Partido Comunista (1848), em Grundrisse (1857-8), artigos publicados no New York Daily Tribune, cadernos de anotações, cartas e outros. Se, de início, o conteúdo de tais referências exprimiria uma "tensão entre a condenação moral dos efeitos da expansão da máquina capitalista e sua certa justificação teórica" (p. 38), textos mais tardios propuseram uma compreensão mais sensível e objetiva dos diferentes mundos. Dois objetos de preocupação dos dois filósofos seriam exemplares: 1) a comuna russa, da qual se tratou no artigo de Engels e nas cartas trocadas por Marx com a ativista russa Vera Zasulich (1849-1919); 2) a assim chamada liga dos iroqueses (grupo indígena habitante do subcontinente norte-americano), conhecida por meio da leitura que Marx fez de obras como a do antropólogo estadunidense Lewis Morgan (1818-1881), estudo que resultou na redação de seus Ethnological notebooks (1880-1882), publicados somente oitenta e nove anos após sua morte. Em ambos os casos, interessava-lhes sobremaneira (a Engels e a Marx) os modos de apropriação coletiva do recurso fundiário e suas implicações no que diz respeito à "diversidade dos caminhos do desenvolvimento histórico dos povos" (p. 61). Ou seja, formações sociais distintas (com ou sem classes, assentadas em apropriação privada ou comunal do solo) foram percebidas pelos dois filósofos como contemporâneas e, acrescenta Tible, "simétricas", uma vez que ambos não mais as encaravam sob a arrogância e a superioridade do pensamento etnocêntrico europeu.

O autor realizou ainda uma leitura detida de outros textos de Marx dentre eles, a Crítica da filosofia do direito de Hegel (1843), A questão judaica e os 
Manuscritos econômico-filosóficos (1844), A guerra civil na França (1871) e a Crítica do Programa de Gotha (1875) -, destacando as conclusões ali contidas sobre a temática do Estado (capítulo 2). Indica haver em seu conjunto um movimento de transição de uma concepção democrático-radical do Estado como instância superior aos conflitos sociais e seu mediador, para um entendimento (fortemente marcado pelos eventos de 1848) do Estado como instrumento burocrático e repressivo de dominação de classe e, finalmente, do Estado como uma órgão político que, ao mesmo tempo, condiciona e viabiliza o funcionamento do sistema de valorização e acumulação de capital, sendo essa última percepção apontada na longa crítica marxiana da economia política, cujo resultado foi a redação inacabada de $O$ capital. Dessa mudança de abordagem derivaria a necessidade de abolição e superação da forma política estatal, o que Tible caracteriza como "ímpeto antiestatista marxiano" (p. 103), tornado ainda mais preciso nas polêmicas de Marx com Mikhail Bakunin (1814-1876) e Ferdinand Lassalle (1825-1864).

O paralelo com o pensamento de Clastres advém, de acordo com Tible, do combate que esse antropólogo francês moveu contra a caracterização das "sociedades primitivas" como sociedades incompletas, marcadas pela ausência de tal ou qual elemento próprio da cultura ocidental (classes sociais, poder político, hierarquias, Estado). Sua antropologia política sugere que as sociedades indígenas não despossuem o Estado - enquanto poder transcendental separado da própria sociedade - por desconhecê-lo, mas sim por recusá-lo ativamente. Assim, mecanismos desenvolvidos a partir de sua base teriam por princípio manter o tecido social indiviso, impedindo o surgimento de autoridades cujas forças eventualmente poderiam se voltar contra os indivíduos horizontalmente organizados. De um lado, chefes locais com poderes limitados mediariam a paz social por meio da oratória e seriam permanentemente vigiados pela própria tribo a que servem. De outro, os conflitos bélicos seriam orgânicos aos grupos por assegurarem sua fragmentação e multiplicidade. Por último, as relações de parentesco e o universo mítico, reproduzidos com base no ideal de reciprocidade, manteriam uma coesão social incompatível com a emergência de um poder coercitivo verticalizado.

A relação entre Marx e Clastres não está dada pelo fato de ambos compartilharem alguma forma de "aversão" pela instituição estatal. Para interligá-los Tible recorre ao entendimento, buscado em Mil Platôs (1980), de Gilles Deleuze (1925-1995) e Félix Guattari (1930-1992), de que o Estado e sua violência precederam a acumulação capitalista, sendo ele o responsável pelo engendramento das classes, e não o contrário. Marx e Clastres convergiriam, pois, "na compreensão do Estado como unificação e transcendência e em 
seus elos decisivos com a exploração" (p. 147). Assim, o Estado capitalista visto sob a ótica de Marx e o perigo latente do Estado nas sociedades indígenas lido sob a lógica de Clastres estariam identificados, tornando os entendimentos dos dois autores análogos e complementares entre si.

As explanações teóricas ganham materialidade quando estão baseadas em situações históricas concretas. Seguindo esse caminho (capítulo 3), o autor passa a estudar algumas "formas" de organização política antagônicas ao Estado, da maneira como se apresentaram a Karl Marx em alguns de seus escritos. A "forma-comuna" e seus conselhos populares, conhecidos pelo aparecimento da Comuna de Paris em 1871 na França, teria exercido grande influência sobre Marx, que a considerou uma evidência do teor de classe do Estado e da necessidade de os trabalhadores tomarem-no para seus próprios fins, o que deveria corresponder, por consequência, à sua supressão. A "forma-confederação", observada a partir da liga dos iroqueses, reuniria diferentes tribos autônomas e independentes em um conselho em que todos os adultos teriam igual participação, e nesse ponto teriam se inspirado nos republicanos estadunidenses à época da redação de sua primeira constituição (p. 156). A "forma-conselho", por sua vez, elemento comum às comunas e confederações, estaria também por trás da Organização Regional dos Povos Indígenas da Amazônia (Orpia), sistema intercomunitário e horizontal do qual participam os Yanomami ainda hoje e ao qual eles recorreram em 1994 pela anulação de uma lei que dividia arbitrariamente seu território.

O autor compreende o pensamento de Davi Kopenawa com base nas circunstâncias históricas em que foi gerado (contato relativamente recente dos Yanomami com o "homem branco", e junto dele suas doenças e mercadorias; presença predatória de garimpeiros na Amazônia desde a década de 1970; esforços pelo ato de demarcação da terra Yanomami, concretizado em 1992). Fruto de uma trajetória singular como intérprete da Funai vindo de um grupo dizimado por epidemias, Kopenawa "articula categorias brancas e indígenas, pois conjuga experiência com os brancos e firmeza intelectual do xamã" (p. 165). Seu discurso, registrado em conjunto com o antropólogo francês Bruce Albert na obra La chute du ciel (2010), apresentaria uma floresta habitada por xapiripë - espíritos verdadeiramente possuidores da floresta e responsáveis por sua ordenação cosmológica e ecológica. A exploração predatória promovida pela atividade garimpeira seria responsável pela emissão de um vapor visto como causador das novas doenças, a xawara, além do próprio aquecimento global.

Segundo Tible, a indistinção entre natureza e cultura subjacente no pensamento de Kopenawa, interpretado com base na obra de Eduardo Vi- 
veiros de Castro, evidencia um perspectivismo assentado sobre alteridade, multiplicidade, diferença. Contra a cobiça do povo cujo pensamento se encontra "fixado nas mercadorias" (p. 167), teríamos então o sistema relacional de reciprocidades Yanomami. Finalmente, a dialética materialista de Marx, que também compreendia natureza e sociedade como totalidade relacional (sua concepção da categoria "produção" seria esclarecedora nesse sentido), é apresentada como outro elemento de aproximação da visão de mundo e da orientação social indígena, sendo ambos (Marx e Kopenawa, no caso) igualmente dotados de críticas profundas à sociedade mercantil, ao capitalismo propriamente dito.

Concepção e defesa de formas coletivas de apropriação dos recursos produtivos; posturas combativas diante do Estado e pela organização autônoma da "forma-conselho"; crítica latente do mundo das mercadorias e de sua ideologia. Tais são, portanto, os elementos sugeridos por Jean Tible para "interpelar" (o termo é várias vezes repetido) o pensamento marxiano com os problemas próprios das sociedades indígenas americanas. O livro termina com uma remissão à antropofagia de Oswald de Andrade, propondo-a como "chave", "ponte" e "catalizador" (p. 204-5) do diálogo entre as duas realidades (marxista e indígena - "deglutição" da primeira pela segunda e vice-versa) e suas correspondentes visões de mundo.

As conclusões do autor nem sempre coincidem com o desenvolvimento real de suas análises e, por vezes, falta alguma dose de rigor. Por exemplo, depois de apresentar diversas evidências de que a obra de Marx conteve sensibilidade contínua pelas sociedades não europeias, embora esse aspecto apenas tardiamente tenha sido ampliado e adquirido consistência teórica, Tible prossegue suas considerações afirmando que Marx tinha "dificuldades" em "apreender as sociedades 'outras'" (p. 122). De maneira correlata, oferecendo claros indícios de que o "antiestatismo" de Marx foi produto de um fazer-se teórico constitutivo e de longa duração, o autor vacila ao tratá-lo ora como fruto de um "deslocamento" (p. 69), ora como um "continuum" de toda sua obra (p. 92). Isso ocorre porque o autor prende-se muito a interpretações oferecidas por fontes secundárias (isto é, por outros comentadores), cujas conclusões na realidade são, muitas vezes, superáveis pelos próprios resultados de sua investigação.

Também se observa um demasiado isolamento de trechos e parágrafos das obras de Marx e Engels para depois examiná-los, levando pouco em conta a maneira pela qual as breves e, por vezes, incertas referências aos povos não europeus e ao Estado se articulam com desenvolvimentos filosóficos e epistemológicos de maior alcance. 
Ademais, a aproximação feita de Marx com Pierre Clastres se baseia exclusivamente na postura antagonista que ambos exerceram com relação ao Estado em seus escritos. Se, como o próprio autor recorda, os dois teóricos tiveram motivações diferentes, utilizaram categorias explicativas e procedimentos analíticos distantes (incluindo suas divergentes concepções de Estado), e adotaram posturas teóricas e metodológicas incongruentes, a simples aversão comum ao Estado não basta para que disso concluamos que ambos são compatíveis apesar de suas claras diferenças. Com isso, não me refiro ao fato de Clastres ter se mostrado, a partir de determinada fase da vida, um antimarxista assíduo em suas polêmicas, mas sim por sua antropologia política divergir diametralmente do materialismo histórico e sua noção basilar de "totalidade dialética".

Isso fica evidente no produtivo debate travado entre Clastres e os antropólogos marxistas franceses durante a década de 1970 e início da seguinte, entre os quais estavam Claude Meillassoux (1925-2005), Maurice Godelier (1934-) e Emmanuel Terray (1935-). Causa surpresa que Tible, ao buscar estabelecer uma aproximação entre antropologia e marxismo, não tenha o cuidado de problematizar os textos daqueles que se afirmaram como adeptos de uma antropologia marxista, hoje praticamente abandonada. Com exceção de três citações isoladas (p. 26, 68 e 122), foram vagamente lembrados como "certos autores marxistas" (p. 123 e 132), aceitando sempre a rejeição de Clastres, sem maiores esclarecimentos.

A contenda, fortemente marcada pelos eventos de maio de 1968, desenrolou-se em torno de dois flancos principais. De um lado, a questão do surgimento do Estado nas sociedades humanas em geral. De outro, a separação ou junção das relações materiais de existência social com suas expressões simbólicas, políticas e culturais - em outras palavras, em torno do uso e os limites dos vocábulos "infraestrutura" e "superestrutura" para a descrição da vida humana em sociedade.

Em L'idéel et le matériel (1984), obra que reflete esses debates e a eles de alguma forma responde, Godelier resolve o problema defendendo a ideia de que a distinção entre infraestrutura e superestrutura não pode ser entendida como uma separação de instituições, tampouco de instâncias ou esferas da vida humana, mas sim de "funções", já que na maior parte das sociedades até agora conhecidas, o parentesco, a religião e a política puderam perfeitamente ser considerados aspectos predominantes em detrimento dos puramente "econômicos", mas isso só ocorreria porque religião, parentesco e política nessas sociedades "funcionam" como instrumentos e parâmetros de organização das relações materiais, individuais e coletivas, necessárias 
à sobrevivência física dos homens. Nesse quadro, o Estado surgiria de um acordo tácito entre dominantes e dominados pela instituição das hierarquias com vista a pautar a coleta e a redistribuição dos recursos produzidos sob critérios imateriais coletivamente compartilhados. ${ }^{2}$

Seguindo essa ótica, percebe-se a impropriedade da antropologia política de Clastres ao propor "que a infraestrutura é o político e a superestrutura é o econômico", ${ }^{3}$ contradizendo sua própria defesa da não autonomia das esferas (ou "fato social total") nas assim chamadas sociedades primitivas. O paralelo de Marx com Clastres aparece, então, desafinado e muito aquém do contato sugerido por Tible entre o mesmo pensador alemão e o Yanomami Davi Kopenawa, aproximação muito mais frutífera e convincente, mas que infelizmente foi menos desenvolvida em Marx selvagem. Pelo viés da crítica à sociedade de mercado, o pensamento indígena talvez prescindisse de qualquer mediação teórica, já que, como o próprio Tible demonstra em seu livro, materialismo histórico e cosmopolíticas ameríndias resultam, ambos, de antagonismos decorrentes da lógica e do modus operandi das relações capitalistas, tanto em seu centro geográfico quanto nas fronteiras, e que por tal razão apresentam resultados semelhantes ou, no mínimo, análogos.

Ao enfatizar o vínculo entre, de um lado, o pensamento dos autores estudados e, de outro, as necessidades, os fenômenos e as práticas sociais de suas épocas, Tible retoma uma concepção de práxis que não se detém em certos usos abstratos da noção de "agência", que apartam determinados grupos de indivíduos do tecido social, deslocando-os parcialmente de seus contextos efetivos e das relações sociais em que se constituem. Aproxima-se, pela concretude da abordagem, de uma ideia de "experiência histórica" tal como empregada pelo historiador britânico E. P. Thompson (1924-1993), isto é: "pessoas que experimentam suas situações e relações produtivas determinadas como necessidades e interesses e como antagonismos, e em seguida "tratam" essa experiência em sua consciência e sua cultura", agindo assim "sobre sua situação determinada". ${ }^{4}$

Não obstante, algo fundamental de que carece Marx selvagem, e que não foi observado por nenhum dos comentários que se fez sobre o livro até o

\footnotetext{
2 Cf. GODELIER, Maurice. Lidéel et le matériel: Pensée, économies, sociétés. Paris: Fayard, 1984.

3 CLASTRES, Pierre. A sociedade contra o Estado. Tradução de Theo Santiago. São Paulo: Cosac Naify, 2013 [1 ${ }^{\text {a }}$ ed. 1974], p. 215.

4 THOMPSON, Edward Palmer. Amiséria da teoria ou um planetário de erros. Rio de Janeiro:Zahar, 1981, p. 182.
} 
momento, ${ }^{5}$ é uma abordagem de teor histórico. Mesmo que não se deva cobrar de seu autor algo que não faz parte de sua proposta - trata-se de uma obra fundamentalmente teórica e conceitual - alguns parágrafos que fossem poderiam ter situado temporalmente a realidade indígena de hoje (bem como a dos iroqueses no século XIX e a dos Yanomami na década de 1990) nos processos de transformação pelos quais passaram os diversos grupos indígenas americanos ao longo dos últimos séculos, seja no que diz respeito às posturas e ações que sobre eles foram adotadas por outros, seja no que toca às transformações de suas próprias práticas, expectativas, interesses e perspectivas históricas ao longo do tempo.

Nesse sentido, não são aspectos indiferentes ao tema, por exemplo: a dinâmica dos primeiros contatos com os europeus; as formas de incorporação das populações indígenas nas distintas sociedades coloniais (sobretudo como força de trabalho, mas também por meio de trocas comerciais, parentesco, catequese e, em alguns casos, alianças políticas); seu lugar nos aldeamentos, reduções e outros espaços religiosos da América colonial; a política indigenista sob as reformas pombalinas e bourbônicas; suas condições jurídicas no Império brasileiro e nas repúblicas independentes sul-americanas; as condições que lhes foram colocadas pela modernização capitalista e as ditaduras militares do século passado etc., para ficar apenas em alguns tópicos recorrentes da literatura histórica recente.

Para finalizar, é preciso dizer que, no conjunto, o livro é instigante e merece ser lido não apenas por cientistas sociais, mas também por historiadores, pois oferece subsídios conceituais interessantes para finalmente compreendermos as populações indígenas, do passado e do presente, em sua condição de agentes sociais concretos, deixando de considerá-los ora como sujeitos passivos, ora como seres culturais abstratos. Ademais, o texto

\footnotetext{
${ }^{5}$ Cf., no próprio volume, Prefácio (Michael Löwy), orelhas (Peter Pál Pelbart), contracapa (Laymert Garcia dos Santos), Posfácio (Carlos Enrique Ruiz Ferreira) e Comentários sobre a obra (Sérgio Cardoso e Marcelo Ridenti). Além disso: ALBUQUERQUE, Hugo. Selvagens do Mundo, Uni-vos! Resenha de Marx selvagem, de Jean Tible. Lugar Comum. Rio de Janeiro: UFRJ, n. 42, 2014; DOMINGUES, Sérgio. Um Marx selvagem e uma esquerda domesticada. Disponível em: <www.diarioliberdade.org/opiniom/opiniom-propia/44977-um-marx-selvagem-e-uma-esquerda-domesticada. html >. Publicado em: 8 jan. 2014 e acesso em: 22 maio 2015; ARANTES, Marília. Marx selvagem, de Jean Tible: descolonização e antropofagia. Disponível em:<http://outraspalavras.net/ blog/2014/05/16/marx-selvagem-de-jean-tible-descolonizacao-e-antropofagia/>. Publicado em: 16 maio 2014 e acesso em: 22 maio 2015; e RUBBO, Deni Alfaro. Resenha de: Jean Tible. Marx selvagem. In: Tempo Social, v. 27, n. 2, 2015.
} 
afina-se ao que Paulo Arantes nomeou de 0 novo tempo do mundo, ${ }^{6}$ primeiro porque compartilha do arsenal vocabular dos movimentos sociais recentes ("lutas", "coletivos", "simetria", "agência" e mesmo, em sentido impreciso, "colonialismo"), depois, porque com ele associa e identifica situações históricas distantes no tempo e no espaço para assim mobilizá-las para a emergência social em uma era de expectativas decrescentes, o que deve constituir mais uma razão para que nós, profissionais do tempo histórico, consideremos o diálogo proposto.

Recebido: 08/06/2015 - Aprovado: 14/12/2015

\footnotetext{
${ }^{6}$ ARANTES, Paulo. O novo tempo do mundo: e outros estudos sobre a era da emergência. São Paulo: Boitempo, 2014.
} 